DOI: $10.31249 / \mathrm{rsm} / 2021.04 .08$

\title{
Г.Г. Мачитидзе
}

\section{COVID-19 И ВОЙНА В АФГАНИСТАНЕ}

Аннотация. В статье исследуются проблемы взаимосвязи между пандемией коронавируса и масштабным вооруженным конфликтом в Афганистане. Важным элементом этой проблемь является деятельность движения «Талибан» ${ }^{1}$ в условиях распространения COVID-19 в стране. В первом разделе автор концентрирует свое внимание на параметрах заболеваемости и характере борьбы с новой инфекцией в стране в условиях слабой системы общественного здравоохранения. Обращается внимание на отсутствие достаточных возможностей тестирования и национального реестра смертей, что затрудняет выявление точных масштабов пандемии. Во втором разделе автор анализирует проблему связанных с пандемией тяжельх соииально-экономических последствий для населения Афганистана - резкий рост безработиць, бедности в условиях, когда экономика, в основном, зависит от внешней помощи. Порожденные пандемией социально-экономические потрясения приводят к радикализации отчаявшихся людей, особенно молодежи, и подталкивают их к пополнению рядов джихадистов. В третьем разделе статьи освещается достаточно гибкая реакиия талибов на пандемию при сохранении четкой линии на противостояние с официальными властями. Автор показывает смену тактики движения «Талибан» от неприятия вакиинации к взаимодействию с неправительственными организациями для оказания медицинских услуг населению отдаленных районов страны. Своевременному предоставлению населению медицинских услуг способствовали ранее созданные талибами сложные системы параллельного управления на контролируемых территориях. Автор приходит к выводу, что, заполнив гуманитарный вакуyм, созданный COVID-19, путем оказания медииинских услуг населению, движение «Талибан» стремится продемонстрировать международному сообществу, что они готовы эффективно управлять государством в будущем после прекращения боевых действий.

Ключевые слова: COVID-19; вооруженный конфликт; движение «Талибан»; система здравоохранения Афганистана; сочиильно-экономические последствия пандемии; вакцинация.

1. «Талибан»-радикальное движение, запрещченное в РФ. 


\title{
РОССИЯ И МИР В ХХІ ВЕКЕ
}

\author{
Мачитидзе Георгий Григорьевич - кандидат исторических наук, \\ старший научный сотрудник Института международных исследований \\ МГИМО МИД РФ. Россия, Москва. \\ E-mail: mggkabul@gmail.com. \\ Scopus Author ID: 57219925034. \\ Web of Science Researcher ID: AAG-5419-2020
}

\section{Machitidze G.G. COVID-19 and the war in Afghanistan}

Abstract. The article examines the relationship problems between the coronavirus pandemic and the large-scale armed conflict in Afghanistan. An important element of this problem is the Taliban activities in the context of the COVID-19 spread in the country. In the first part, the author focuses on the parameters of morbidity and the nature of the fight against a new infection in the country in a weak public health system. Attention is drawn to the lack of adequate testing capacity and a national death registry, making it difficult to pinpoint the exact extent of the pandemic. In the second part, the author analyzes the problem of severe socio-economic consequences associated with the pandemic for the population of Afghanistan - a sharp increase in unemployment, poverty in an environment where the economy is mainly dependent on external assistance. The socio-economic upheaval caused by the pandemic is radicalizing desperate people, especially young people, and pushing them to join the ranks of the jihadists. The third part of the article highlights the Taliban's rather flexible response to the pandemic while maintaining a clear line on confrontation with the official authorities. The author shows the change in tactics of the Taliban movement from a rejection of vaccination to interaction with non-governmental organizations to provide medical services to the population of remote regions of the country. The timely provision of medical services to the population was facilitated by the complex parallel control systems previously created by the Taliban in the controlled territories. The author concludes that by filling the humanitarian vacuum created by COVID-19 by providing health services to the population, the Taliban are committed to demonstrating to the international community that they are ready to effectively rule the state in the future after the end of hostilities.

Keywords: COVID-19; armed conflict; Taliban; Afghanistan's health system; socioeconomic impact of the pandemic; vaccination.

Machitidze Georgy Grigorievich - Candidate of Historical Sciences, Senior Fellow of Institute for International Studies of MGIMO (University). Russia, Moscow.

E-mail: mggkabul@gmail.com.

Scopus Author ID: $\mathbf{5 7 2 1 9 9 2 5 0 3 4}$

Web of Science Researcher ID: AAG-5419-2020 


\section{Борьба с COVID-19 в Афганистане}

Пандемия коронавируса привела к ослаблению системы здравоохранения и замедлению экономического роста Исламской Республики Афганистан (ИРА), находящейся в условиях длительного вооруженного конфликта между властями и талибами. В то время как афганское правительство вынуждено бороться с обострившимися социально-экономическими проблемами, движение «Талибан», скорректировав свой «образ действий», старается использовать связанные с пандемией сложности в собственных интересах. К талибам и афганскому обществу вполне применима характеристика, данная известным российским ученым В.В. Наумкиным: «Силы исламистского движения выше в тех ближневосточных и средне-восточных обществах, которые можно отнести к глубоко разделенным и которые стали объектами силового внешнего вмешательства» [Насильственные конфликты 2016]. Эксперты Всемирной организации здравоохранения (ВО3) полагают, что система охраны здоровья в Афганистане по-прежнему остается одной из худших в мире. На июнь 2021 г. в Афганистане зафиксировано 120216 случаев заболевания коронавирусом, от которого и его последствий погибли 4962 человека. Полную вакцинацию прошли 187654 человека, т.е. 0,58\% населения. Однако фактическое число случаев заболевания и смертельных исходов, вероятно, намного выше из-за отсутствия надежных данных, неадекватной системы общественного здравоохранения, ограниченных возможностей тестирования и отсутствия национального реестра смертей. Поэтому точные масштабы распространения пандемии трудно определить. В деревнях умирали по нескольку десятков человек, а всего по всей стране насчитывается приблизительно 40 тыс. деревень. Некоторые исследования относительно распространенности коронавируca, проведенные в середине 2020 г., показали, что на самом деле в Афганистане могут быть инфицированы сотни тысяч человек [Prabhu 2021]. Столь плачевная ситуация связана, в первую очередь, с продолжающимся конфликтом, изза которого люди не могут получить самые элементарные услуги, в том числе гуманитарную помощь. Не исключено, что страну может ждать катастрофа, если жители не будут соблюдать меры санитарной предосторожности.

Власти предупредили о нехватке кислорода в медицинских учреждениях, a еще раньше сообщили о приостановке кампании вакцинации из-за нехватки вакцин. В рамках глобальной международной программы COVAX Кабул в феврале 2021 г. безвозмездно получил вакцину AstraZeneca из Индии, а также вакцину Sinopharm из Китая. Несмотря на все сложности, Кабул планирует развернуть работу по вакцинации против COVID-19 в самых отдаленных уголках страны. Задача Министерства здравоохранения - вакцинировать $20 \%$ населения в этом году и $60 \%$ к концу 2022 г. Однако нельзя не учитывать, что Министерство здравоохранения предлагает прямые услуги только в трех провинциях - 
Панджшер, Парван и Каписа, остальное делается через партнерские неправительственные организации (НПО) и частных медицинских работников. Власти рассчитывают, что как местные, так и международные гуманитарные организации пойдут даже в те районы, которые правительство не полностью или вообще не контролирует. Сложность эффективной борьбы с пандемией коронавируса в Афганистане состоит в том, что на протяжении последних 20 лет Афганистан находится в состоянии перманентного вооруженного конфликта, причем боевые столкновения происходят в большинстве афганских провинций. Почти $30 \%$ уездов страны считаются «труднодоступными» из-за удаленности и множества других вооруженных формирований, борющихся за контроль над территориями. Необходимо также иметь в виду, что две трети населения Афганистана являются поденщиками, не имеющими необходимых социальных и финансовых гарантий, поэтому довольно сложно, а иногда почти невозможно наложить ограничения на их передвижение. Мешают также периодически возникающие по инициативе отдельных полевых командиров «Талибана» угрозы работникам здравоохранения и глобальные сбои в поставках вакцин.

В апреле 2020 г. к кампании против COVID-19 присоединилось и Министерство по делам хаджа и религии Афганистана, объявив об ограничении пятничных и регулярных молитв в мечетях [Ansar 2020]. Вслед за этим решением Высшая комиссия улемов по борьбе с коронавирусом наложила запрет на все религиозные, политические и культурные собрания до полного искоренения COVID-19 в стране. Религиозные деятели призвали людей обращать внимание на советы по здоровью, заявив, что решение основано на Коране и хадисах. Высшая комиссия и министерство призвали людей проводить похороны, умерших от коронавируса в соответствии с особыми мерами предосторожности и с меньшим количеством родственников. Глава комиссии Абдул Салам Абид призвал правительство освободить людей от налогов, а бизнесменов помогать уязвимым людям до тех пор, пока ситуация не нормализуется.

В настоящее время в Афганистане обнаружены различные штаммы коронавируса при недостаточном тестировании потенциальных случаев заболевания. В стране отсутствует тест-система для выявления индийского штамма, в связи с чем растет обеспокоенность по поводу его распространения. Из-за ограниченных ресурсов общественного здравоохранения, а также отсутствия национального реестра смертей, подтвержденные случаи смерти от COVID-19, вероятно, в целом по Афганистану будут занижены. Несоблюдение рекомендаций общественного здравоохранения в ИРА создают серьезные риски в обществе, поскольку люди, как правило, не соблюдают правила физического дистанцирования или ношения масок. В ответ на быстрый рост числа новых случаев заболевания Министерство здравоохранения объявило о двухнедельном закрытии школ, университетов и учебных курсов с 29 мая 2021 г. в 16 провинциях, включая Кабул. Какие-либо другие общенациональные меры изоляции отсутствуют. 
В то же время Министерство здравоохранения Афганистана создало свыше 2 тыс. пунктов для вакцинации по всей стране во взаимодействии с неправительственными организациями, которые работают в подконтрольных талибам районах. Благодаря новым потокам чрезвычайного финансирования, сеть из 28 лабораторий была построена в 25 афганских провинциях [Prabhu 2021]. Вместе с тем сохраняется серьезная озабоченность по поводу равного доступа к вакцинам для афганцев, особенно уязвимых групп, таких как перемещенные лица, репатрианты и кочевое население, а также люди, живущие в труднодоступных районах. Охват вакцинацией всех групп мигрантов крайне ограничен из-за негативного восприятия и препятствий для доступа к медицинской помощи. Необходимы также дополнительные усилия для охвата вакцинацией женщин и людей, живущих в неподконтрольных правительству районах. Внедрение вакцины происходит медленно, необходимы постоянные усилия по информированию о рисках и вовлечению населения, чтобы группы населения с высоким риском и непосредственный персонал понимали преимущества вакцинирования. Приоритетной задачей является противодействие негативным слухам о вакцине. Не обеспечены надлежащее оснащение лабораторий и обслуживающего персонала, а также транспарентная доставка закупленных материалов в малообеспеченные медицинские центры по всей стране [Afghanistan: Strategic 2021].

\section{Социально-экономические послеАствия COVID-19}

Пандемия коронавируса нанесла серьезный ущерб экономике Афганистана. ВВП сократился примерно на 5,0\% в 2020 г., поскольку меры по сдерживанию COVID-19 усугубили экономические последствия постоянного насилия и политической нестабильности [Afghanistan's Economy 2021]. Постоянный представитель Афганистана при ООН Адела Раз, подтвердив информацию о том, что пандемия нанесла серьезный урон экономике страны, одновременно указала на резкий рост безработицы, когда миллионы людей оказались за чертой бедности. Параллельно эпидемиологический кризис привел к массовому возвращению афганских беженцев из соседних стран [Афганистан: пандемия 2021].

Афганистан как страна, охваченная длительным, масштабным вооруженным конфликтом, вынужден будет нести последствия пандемии в условиях, когда экономика в основном зависит от внешней помощи, которая должна поступать непрерывно. ИРА в значительной степени зависит от импорта, годовой объем которого составил в 2020 г. 6,5 млрд долл. США, в то время как объем экспорта не превышал 800 млн долл. [Afghanistan annual 2021]. Частный сектор чрезвычайно узок, а занятость сосредоточена в сельском хозяйстве с низкой производительностью. Развитие и диверсификация частного сектора сдерживаются не только отсутствием безопасности, но и политической 


\section{РОССИЯ И МИР В ХХІ ВЕКЕ}

нестабильностью, слабостью институтов, неадекватной инфраструктурой, широко распространенной коррупцией и сложной деловой средой. Афганистан занял 173-е место из 190 стран в соответствующем обзоре Мирового банка [Doing Business 2020]. Около 75\% государственных расходов финансируются с помощью грантов, хотя объемы внешней помощи снизились с примерно $100 \%$ ВВП в 2009 г. до $43 \%$ ВВП в 2020 г. Незаконная экономика составляет значительную долю производства, экспорта и занятости, включая производство опия, контрабанду и незаконную добычу полезных ископаемых.

Следует отметить и ряд ограничений и рисков, с которыми сталкивается Афганистан при планировании своего экономического развития. Ощущается неспособность властей мобилизовать внутренние ресурсы из-за проблем с безопасностью, большой неформальной экономики и неэффективного сбора доходов. Экономика Афганистана в значительной степени зависит от торговли через территорию Пакистана, что ставит ее в сильную зависимость от данного внешнего фактора. Инфляция определяется уровнем импорта, а экспортным рынкам не хватает сравнительных преимуществ для конкуренции на региональном или международном уровнях. Сохраняются необоснованные завышенные ожидания от частного сектора, у которого нет или мало стимулов для выхода на рынки, где нестабильность и коррупция очень высоки, что наносит ущерб инвестициям и финансовым потокам. Кроме того, Афганистан страдает от множества целей, задач, конвенций, рамок и условий, налагаемых международными донорами на государственные учреждения. Предоставление базовых услуг принесено в жертву достижению целей, установленных зарубежными странами, и управлению громоздкой административной работой.

Для более эффективной борьбы с пандемией коронавируса следовало бы больше внимания уделять получению гуманитарной помощи, для чего правительству, государственным деятелям и частному сектору необходимо работать сообща при условии сохранения зависимости от помощи международных партнеров и учреждений, занимающихся вопросами развития [Rahim 2020]. Кроме того, созданию благоприятных условий для инвестиций международных партнеров могли бы способствовать реальный прогресс на мирных переговорах между афганским правительством и «Талибаном», урегулирование разногласий внутри правящих элит страны, а также принятие мер по предотвращению межэтнической напряженности. Пока ожидается сокращение помощи в целом примерно на $20 \%$ по сравнению с предыдущим периодом взносов в 2016-2020 гг. (15,2 млрд долл.) [Rahimi 2020]. Нельзя также не отметить, что порожденные пандемией социально-экономические потрясения приводят к радикализации отчаявшихся людей, особенно молодежи, и подталкивают их к пополнению рядов джихадистов. Вызванный распространением коронавируса экономический спад и неспособность правительства Афганистана оказать помощь всем нуждающимся будут усиливать градус политической напряженности в стране. 


\section{COVID-19: вызовы и возможности Аля Авижения "Талибан"}

В начальный период пандемии у мирового сообщества были не вполне обоснованные надежды на то, что вирус может побудить экстремистские группировки приостановить боевые действия. Вероятно, рассчитывая на это, Генеральный секретарь ООН Антониу Гутерриш 23 марта 2020 г. призвал вооруженные стороны прекратить боевые действия [Кapur 2021]. Однако что касается талибов в Афганистане, то они проявляют готовность оказать людям помощь при сохранении четкой линии на противостояние с официальными властями. Первоначально представители движения «Талибан» с момента появления коронавируса в Афганистане в феврале 2020 г. призвали население подумать о положительной стороне пандемии. Позитивным, по их мнению, было то, что распространение вируса приведет к уменьшению числа прелюбодеяний, в преддверии конца света люди станут честнее, больше будут заботиться о стариках, а также о чистоте тела, увеличится богобоязненность, сократится миграция мусульман в страны Запада [Волков 2020].

На самом деле это была своеобразная реакция руководства движения на пугающую неизвестность, которая могла привести к распространению паники, в том числе среди боевиков «Талибана». Среди талибов были распространены опасения, что официальные лица, занимающиеся вакцинацией против полиомиелита, использовали эту кампанию как уловку для сбора разведданных о повстанцах. В новых условиях, осознав, что пандемия коронавируса приобретает характер чрезвычайной ситуации в области общественного здравоохранения, талибы сменили тактику, решив использовать участие в борьбе c COVID-19, в том числе для повышения уровня политического влияния в афганском обществе. 18 марта 2020 г. «Талибан» опубликовал заявление, в котором утверждалось, что Бог послал вирус в ответ на «неповиновение» и «грехи человечества» [Statement of Islamic 2020]. Такое поведение является скорее всего частью более широкой стратегии, направленной на дальнейшую легитимизацию движения. Активизировались пропагандистская и, соответственно, вербовочная деятельность группировки. Новый «модус операнди» движения «Талибан» свидетельствовал об изменении подходов его руководства к реализации программ иммунизации населения страны в широком смысле этого слова. Напуганные перспективой расширения пандемии коронавируса в контролируемых ими частях Афганистана, талибы заявили о своей готовности работать с медицинскими работниками, а не убивать их, в чем их обвиняли в прошлом. Хотя справедливости ради следует отметить, что еще в сентябре 2019 г. в результате достигнутых договоренностей в Дохе (Катар) «Талибан» отменил пятимесячный запрет для сотрудников Международного комитета Красного Креста и других гуманитарных организаций 
работать в Афганистане [Chappell 2019]. Талибы прекрасно понимали, что ограниченные ресурсы препятствуют их усилиям в борьбе с инфекцией и сами обратились за неотложной помощью к международным гуманитарным организациям, одновременно поставив властям условие: внедрять вакцину против коронавируса в координации с комиссией по здравоохранению движения «Талибан». Представитель «Талибана» Забиулла Муджахид в связи с этоим заявил, что «если вакцина от короны будет внедрена во взаимодействии с нашей комиссией по здравоохранению и в соответствии с нашими принципами, мы согласимся с этим» [Afghanistan's COVID-19 2021]. На практике получилось, что власти были вынуждены прислушаться к мнению талибов, будучи неспособными оказать людям помощь во многих районах страны. Коррумпированность чиновничьей среды в афганских провинциях лишь способствовала укреплению сотрудничества между НПО и талибами, за счет чего последние получают возможность обеспечить более быстрый доступ населения к вакцинации.

Анализ конкретных действий движения «Талибан» в условиях пандемии свидетельствует о том, что группировкой предпринимались определенные меры, которые помогали государственным структурам бороться с пандемией. Так, в марте 2020 г. боевики «Талибана» арестовали в провинции Балх сбежавшего пациента с положительным результатом на коронавирус и вернули его органам здравоохранения. Талибы также распространяли информацию о COVID-19 в контролируемых повстанцами районах Афганистана, поддерживали государственных медицинских работников, которые лечили зараженных пациентов, предложив им безопасный проезд, а также просили афганских репатриантов из Ирана пройти тестирование на COVID-19. В этот же период талибы начали кампанию по информированию общественности о правилах поведения в условиях пандемии в различных провинциях. Причем в одной части одного и того же района уезда могли происходить вооруженные столкновения, а в другой проводиться кампания по информированию населения. Трудно полностью согласиться с утверждением некоторых иностранных исследователей, что реакция террористических группировок на пандемию осуществляется в форме тщательно продуманной пропаганды, которую эти группировки сами и создают. Например, Б. Фармер и С. Юсуфзай отмечают, что пропагандистские видео, где изображается как талибы информируют население о коронавирусе, лишь создает видимость участия движения «Талибан» в борьбе с этой инфекцией [Farmer, Yousafzai 2020]. Кстати, правительственные силы аналогичным образом используют предоставление услуг как инструмент, чтобы завоевать «сердца и умы» людей в рамках стратегии борьбы с повстанцами.

На самом деле реальная польза от деятельности членов движения «Талибан» в контролируемых ими районах очевидна. В отдельных провинциях та- 
либы назначили своих директоров общественного здравоохранения. Боевики «Талибана» с автоматами АК-47, полностью снабженные медицинскими средствами индивидуальной защиты, организовали семинары по предотвращению заражения коронавирусом. Повсеместно в контролируемых районах представители движения распространяли брошюры с советами по профилактике инфекции, а также потребовали отменить все публичные собрания, свадьбы и попросили людей молиться дома, а не в мечетях, использовать маски и перчатки, мыть руки с мылом, в том числе и перед молитвой. В некоторых местах боевики «Талибана» использовали наборы для тестирования на COVID-19, не раскрывая кто им предоставил эти комплекты. Талибы даже подготовили для сельских жителей список овощей, содержащих большое количество витамина $\mathrm{C}$, в целях повышения иммунитета. Кроме того, талибы ввели изоляцию в пострадавших районах, поместив людей с подозрением на COVID-19 в карантин, организовали лагеря для наблюдения и повышения осведомленности в районах, находящихся под их контролем, привлекли старейшин для принятия мер против распространения пандемии. Инициативы талибов, сколь бы сюрреалистичны они ни казались многим афганцам и иностранцам, были положительно встречены Министерством здравоохранения Афганистана [Hamid 2020]. Нельзя не признать, что благодаря изменению позиции руководства движения «Талибан» по отношению к проблеме иммунизации населения страны вакцины против COVID-19 распространились практически по всем провинциям и большинству уездов. Хотя это не означает, что нет срывов в поставках вакцин в связи с нестабильностью, вызванной продолжающимися террористическими актами и вооруженными столкновениями, в которых участвуют не только талибы. Кроме того, движение «Талибан» проявило обеспокоенность по поводу распространения коронавируса в государственных тюрьмах, где нет санитарно-гигиенических и медицинских учреждений. Повстанцы также ввели новое правило, согласно которому афганцы, возвращающиеся из Ирана, где особенно распространилась пандемия, должны были пройти двухнедельный обязательный карантин в своих домах, в отличие от неадекватной проверки властями тысяч афганцев, въезжавших в страну каждый день. Можно предположить, что одним из факторов позитивного реагирования талибов на необходимость участия в вакцинировании стало заражение вирусом многих высокопоставленных членов движения «Талибан», включая лидера Хайбатуллу Ахундзада и его заместителя Сираджуддина Хаккани [O’ Donnell, Khan 2020]. Был также вакцинирован весь личный состав политического офиса талибов в Дохе (Катар).

Борьбе «Талибана» с COVID-19 в Афганистане способствовали ранее созданные им сложные системы параллельного управления на контролируемых территориях. В частности, талибы управляют судами, взимают налоги, контролируют распределение продуктов питания и строительство инфра- 
структуры, содержат свой управленческий аппарат и службу безопасности. Подобная система зачастую позволяет им быстрее предоставлять необходимые услуги по сравнению с афганским правительством. Тем более, что в афганском обществе существуют вполне оправданные опасения по поводу справедливого распределения вакцины среди населения, учитывая, что многие государственные чиновники были осуждены за незаконное присвоение средств, выделенных на борьбу с COVID-19 [Zucchino, Rahim 2021]. Проблема в том, что многие афганцы по-прежнему воспринимают COVID-19 как обман или преувеличение, а не как серьезную угрозу общественному здоровью. «Талибан» может сыграть еще бо́льшую роль в продвижении вакцины против COVID-19, чтобы повысить общественное доверие к кампании вакцинации в стране.

Однако на практике кампания по вакцинации в Афганистане проходила в нестабильной обстановке на фоне непрекращающихся боевых действий между афганскими силами безопасности и повстанцами. Так, в первой половине 2020 г. уровень насилия в Афганистане колебался в связи с переговорным процессом между США и движением «Талибан». С 22 по 28 февраля 2020 г., накануне подписания соглашения, талибы продемонстрировали способность контролировать уровень насилия, который был значительно ниже, чем исторические нормы. После заключения соглашения между США и «Талибаном» 29 февраля 2020 г. уровень насилия увеличился, хотя летальность оставалась ниже исторических норм. Во второй половине 2020 г. талибы совершили многочисленные вооруженные нападения на официальных лиц, гражданских активистов, журналистов, блок-посты афганских сил безопасности. Исключением стали лишь два коротких периода в конце мая и в конце июля 2020 г. во время религиозных праздников Ураза-байрам и Курбан-байрам соответственно, когда талибы объявили о двух трехдневных перемириях. В эти периоды уровень насилия значительно снизился, но вернулся к высокому уровню сразу после прекращения огня. В целом же 2020-й год стал самым кровопролитным годом в Афганистане, когда-либо зарегистрированным ООН, которая зафиксировала более 25 тыс. инцидентов, что на 10\% больше, чем в 2019 г. Беспрецедентные масштабы насилия зимой сохранились и в 2021 г.: в период с 1 января по 31 марта по всей стране было зарегистрировано 7177 инцидентов в сфере безопасности, что на $61 \%$ больше, чем за тот же период 2020 г. [Twelfth report 2021]. Практика показывает, что военная активность талибов не была увязана тесным образом с пандемией. Несмотря на призывы $\mathrm{OOH}$ талибы отказывались из-за пандемии прекратить огонь, хотя и подходили к этому вопросу дифференцированно в зависимости от эпидемиологической обстановки в районах, находящихся под их контролем. 
Пандемия сильно ударила по Афганистану, который еще до ее начала страдал от масштабного вооруженного конфликта, экономической рецессии, нищеты и голода. В результате распространения COVID-19 в стране ослабла система общественного здравоохранения, продолжается серьезный экономический кризис.

«Талибан» интерпретировал пандемию как бедствие, использовал образовавшийся гуманитарный вакуум путем оказания медицинских услуг населению, одновременно активизировав атаки на правительственные силы. Тем самым талибы стремились продемонстрировать международному сообществу, что они готовы эффективно управлять государством в будущем после прекращения боевых действий. Кроме того, «Талибан» умело использовал свое участие в борьбе с пандемией для привлечения в свои ряды новых членов, повышения уровня доверия к себе в обществе в расчете на политическую поддержку в перспективе, укрепление своего авторитета в качестве нового «государственного субъекта».

Главной целью и мотивацией «Талибана», несмотря на COVID-19, попрежнему оставалась борьба против «иностранной оккупации» страны и «марионеточного режима», находящегося у власти в Афганистане. Для того, чтобы пандемия кардинально изменила образ мыслей и поведение талибов, она должна приобрести совершенно неуправляемый характер, близкий к катастрофическим последствиям для широких слоев населения страны. Таким образом, эпидемиологические ограничения в контексте масштабного вооруженного конфликта в стране в целом не повлияли на военную активность движения «Талибан», которое, сохранив достаточно высокую траекторию насилия в стране, в конечном итоге пришло к власти в Афганистане.

\section{Библиография}

Афганистан: пандемия, экономический кризис, насилие // Новости ООН. 2021. 2 фев. URL: https://news.un.org/ru/story/2021/02/1395682 (дата обращения: 03.07.2021).

Волков К. Афганские талибы нашли положительные стороны в пандемии коронавируса // Российская газета. 2020. 29 марта. URL: https://rg.ru/2020/03/29/afganskie-taliby-nashli-polozhitelnyestorony-v-pandemii-koronavirusa.html (дата обращения: 04.05.2021).

Насильственные конфликты и внешнее вмешательство на Ближнем и Среднем Востоке через призму теории глубоко разделенных обществ (ТГРО) // Политическая наука перед вызовами глобального и регионального развития / Под общ. ред. О.В. Гаман-Голутвиной. М.: Аспект Пресс, 2016. С. 415-443 (Российская политическая наука. Истоки и перспективы).

Afghanistan annual imports // Trading Economics. 2021. URL: https://tradingeconomics.com/ afghanistan/imports (дата обращения: 29.05.2021).

Afghanistan: Strategic Situation Report: COVID-19. N 98 (03 June 2021) / United Nations Office for the Coordination of Humanitarian Affairs of the United Nations. URL: https://www. 


\section{РОССИЯ И МИР В ХХІ ВЕКЕ}

humanitarianresponse.info/sites/www.humanitarianresponse.info/files/documents/files/strategic_sitrep covid-19_3_june_2021_final.pdf (дата обращения: 22.05.2021).

Afghanistan's COVID-19 vaccine rollout plans cross conflict front lines // The New Humanitarian. 2021. 7 Apr. URL: https://www.thenewhumanitarian.org/2021/04/07/afghanistan-s-covid-19-vaccinerollout-plans-cross-conflict-front-lines (дата обращения: 12.06.2021).

Afghanistan's Economy to Rebound in 2021 Despite Challenges // Asian Development Bank. 2021. 28 Apr. URL: https://www.adb.org/news/afghanistan-economy-rebound-2021-despite-challenges$\mathrm{adb}$ (дата обращения: 25.05.2021).

Ansar M. Afghan Clerics Ban Religious, Political Gatherings Amid COVID-19 // TOLOnews Reporter. 2020. 05 Apr. URL: https://tolonews.com/health/afghan-clerics-ban-religious-politicalgatherings-amid-covid-19 (дата обращения: 19.05.2021).

Chappell B. Taliban Lift Ban On Red Cross, Pledge To Protect Aid Workers In Afghanistan // National Public Radio. 2019. 16 Sept. URL: https://www.npr.org/2019/09/16/761152686/taliban-liftsban-on-red-cross-pledges-to-protect-aid-workers (дата обращения: 09.06.2021).

Doing Business 2020 // World Bank Group. 2020. URL: https://documents1.worldbank.org/ curated/en/688761571934946384/pdf/Doing-Business-2020-Comparing-Business-Regulation-in-190Economies.pdf (дата обращения: 30.05.2021).

Farmer B., Yousafzai S. Protection or propaganda? Taliban swaps weapons for disinfectant in coronavirus public health video // The Telegraph. 2020. 14 Apr. URL: https://www.telegraph.co.uk/ global-health/science-and-disease/protection-propaganda-taliban-swaps-weapons-disinfectant-coronavirus/ (дата обращения: 10.06.2021).

Hamid T. Taliban Launches Awareness Campaign on Coronavirus // TOLO news. 2020. 29 Mar. URL: https://tolonews.com/index.php/health/taliban-launches-awareness-campaign-coronavirus (дата обращения: 15.06.2021).

Kapur R. The Afghan Taliban and COVID-19 // MEI@75. 2021. 13 Apr. URL: https://www. mei.edu/publications/afghan-taliban-and-covid-19-leveraging-crisis-or-change-heart (дата обращения: 03.06.2021).

O’ Donnell L., Khan M. Taliban Leadership in Disarray on Verge of Peace Talks // Foreign Policy. 2020. 29 May. URL: https://foreignpolicy.com/2020/05/29/taliban-leadership-disarray-coronavirus-covidpeace-talks/ (дата обращения: 11.06.2021).

Prabhu M. Resourceful Optimism: Fighting COVID-19 in Afghanistan // GAVI. 2021. 20 Apr. URL: https://www.gavi.org/vaccineswork/resourceful-optimism-fighting-covid-19-afghanistan (дата обращения: 15.05.2021).

Rahim S.A. What the COVID-19 Outbreak Means for Afghanistan's Troubled Economye? // The Diplomat. 2020. URL: https://thediplomat.com/2020/04/what-the-covid-19-outbreak-means-forafghanistans-troubled-economy/ (дата обращения: 04.05.2021).

Rahimi L. Thinking More Deeply About Human Development in Afghanistan // The Diplomat. 2020. 29 Dec. URL: https://thediplomat.com/2020/12/thinking-more-deeply-about-human-developmentin-afghanistan/ (дата обращения: 02.06.2021).

Statement of Islamic Emirate concerning fight against corona virus // Voice of Jihad. 2020. 18 Mar. URL: http://alemarahenglish.com/?p=33722 (дата обращения: 08.06.2021).

Twelfth report of the Analytical Support and Sanctions Monitoring Team submitted pursuant to resolution 2557 (2020) concerning the Taliban and other associated individuals and entities constituting a threat to the peace stability and security of Afghanistan / United Nations Security Council. URL: https://www.ecoi.net/en/file/local/2053487/S_2021_486_E.pdf (дата обращения: 17.06.2021).

Voice of Jihad. (2020 a, January 20). Statement by commission for the control and regulation of NGOs and companies regarding severe weather // Voice of Jihad. 2020. 20 Jan. URL: http:// alemarahenglish.com/?p=31499 (дата обращения: 11.06.2021). 
Zucchino D., Rahim N. Where a Vaccination Campaign Faces Skepticism, War and Corruption // The New York Times. 2021. 23 Feb. URL: https://www.nytimes.com/2021/02/23/world/asia/afghanistanvaccine-corruption.html (дата обращения: 15.06.2021).

\section{References}

Afganistan: pandemiia, ekonomicheskii krizis, nasilie [Afghanistan: pandemic, economic crisis, violence]. Novosti OON [UN News]. 2021. 2 fev. URL: https://news.un.org/ru/story/2021/02/ 1395682 (date of access: 03.07.2021). (In Russ.)

Afghanistan annual imports. Trading Economics. 2021. URL: https://tradingeconomics.com/ afghanistan/imports (date of access: 29.05.2021).

Afghanistan: Strategic Situation Report: COVID-19. N 98 (03 June 2021). United Nations Office for the Coordination of Humanitarian Affairs of the United Nations. URL: https://www. humanitarianresponse.info/sites/www.humanitarianresponse.info/files/documents/files/strategic_sitrep_ covid-19_3_june_2021_final.pdf (date of access: 22.05.2021).

Afghanistan's COVID-19 vaccine rollout plans cross conflict front lines. The New Humanitarian. 2021. 7 Apr. URL: https://www.thenewhumanitarian.org/2021/04/07/afghanistan-s-covid-19-vaccinerollout-plans-cross-conflict-front-lines (date of access: 12.06.2021).

Afghanistan's Economy to Rebound in 2021 Despite Challenges. Asian Development Bank. 2021. 28 Apr. URL: https://www.adb.org/news/afghanistan-economy-rebound-2021-despite-challengesadb (date of access: 25.05.2021).

Ansar M. Afghan Clerics Ban Religious, Political Gatherings Amid COVID-19. TOLOnews Reporter. 2020. 05 Apr. URL: https://tolonews.com/health/afghan-clerics-ban-religious-politicalgatherings-amid-covid-19 (date of access: 19.05.2021).

Chappell B. Taliban Lift Ban On Red Cross, Pledge To Protect Aid Workers In Afghanistan. National Public Radio. 2019. 16 Sept. URL: https://www.npr.org/2019/09/16/761152686/taliban-liftsban-on-red-cross-pledges-to-protect-aid-workers (date of access: 09.06.2021).

Doing Business 2020. World Bank Group. 2020. URL: https://documents1.worldbank.org/ curated/en/688761571934946384/pdf/Doing-Business-2020-Comparing-Business-Regulation-in-190Economies.pdf (date of access: 30.05.2021).

Farmer B., Yousafzai S. Protection or propaganda? Taliban swaps weapons for disinfectant in coronavirus public health video. The Telegraph. 2020. 14 Apr. URL: https://www.telegraph.co.uk/ global-health/science-and-disease/protection-propaganda-taliban-swaps-weapons-disinfectant-coronavirus/ (date of access: 10.06.2021).

Hamid T. Taliban Launches Awareness Campaign on Coronavirus. TOLO news. 2020. 29 Mar. URL: https://tolonews.com/index.php/health/taliban-launches-awareness-campaign-coronavirus (date of access: 15.06.2021).

Kapur R. The Afghan Taliban and COVID-19. MEI@75. 2021. 13 Apr. URL: https://www.mei. edu/publications/afghan-taliban-and-covid-19-leveraging-crisis-or-change-heart (date of access: 03.06.2021).

Nasil'stvennye konflikty i vneshnee vmeshatel'stvo na Blizhnem i Srednem Vostoke cherez prizmu teorii gluboko razdelennykh obshchestv (TGRO) [Violent conflicts and external intervention in the Near and Middle East through the prism of the theory of deeply divided societies (TDDS)]. Politicheskaia nauka pered vyzovami global'nogo i regional'nogo razvitiia [Political Science Facing the Challenges of Global and Regional Development]. Ed. by O.V. Gaman-Golutvina. Moscow: Aspekt Press, 2016. P. 415-443. (Russian political science. Origins and perspectives). (In Russ.) 


\section{РОССИЯ И МИР В ХХІ ВЕКЕ}

O' Donnell L., Khan M. Taliban Leadership in Disarray on Verge of Peace Talks. Foreign Policy. 2020. 29 May. URL: https://foreignpolicy.com/2020/05/29/taliban-leadership-disarray-coronaviruscovid-peace-talks/ (date of access: 11.06.2021).

Prabhu M. Resourceful Optimism: Fighting COVID-19 in Afghanistan. GAVI. 2021. 20 Apr. URL: https://www.gavi.org/vaccineswork/resourceful-optimism-fighting-covid-19-afghanistan (date of access: 15.05.2021).

Rahim S.A. What the COVID-19 Outbreak Means for Afghanistan's Troubled Economye? The Diplomat. 2020. URL: https://thediplomat.com/2020/04/what-the-covid-19-outbreak-means-forafghanistans-troubled-economy/ (date of access: 04.05.2021).

Rahimi L. Thinking More Deeply About Human Development in Afghanistan. The Diplomat. 2020. 29 Dec. URL: https://thediplomat.com/2020/12/thinking-more-deeply-about-human-developmentin-afghanistan/ (date of access: 02.06.2021).

Statement of Islamic Emirate concerning fight against corona virus. Voice of Jihad. 2020. 18 Mar. URL: http://alemarahenglish.com/?p=33722 (date of access: 08.06.2021).

Twelfth report of the Analytical Support and Sanctions Monitoring Team submitted pursuant to resolution 2557 (2020) concerning the Taliban and other associated individuals and entities constituting a threat to the peace stability and security of Afghanistan. United Nations Security Council. URL: https://www.ecoi.net/en/file/local/2053487/S_2021_486_E.pdf (date of access: 17.06.2021).

Voice of Jihad. (2020 a, January 20). Statement by commission for the control and regulation of NGOs and companies regarding severe weather. Voice of Jihad. 2020. 20 Jan. URL: http:// alemarahenglish.com/?p=31499 (date of access: 11.06.2021).

Volkov K. Afganskie taliby nashli polozhitel'nye storony v pandemii koronavirusa [Afghan Taliban find positives in coronavirus pandemic]. Rossiiskaia gazeta [Russian newspaper]. 2020. 29 Mar. URL: https://rg.ru/2020/03/29/afganskie-taliby-nashli-polozhitelnye-storony-v-pandemii-koronavirusa. html (date of access: 04.05.2021). (In Russ.)

Zucchino D., Rahim N. Where a Vaccination Campaign Faces Skepticism, War and Corruption. The New York Times. 2021. 23 Feb. URL: https:/www.nytimes.com/2021/02/23/world/asia/afghanistanvaccine-corruption.html (date of access: 15.06.2021). 